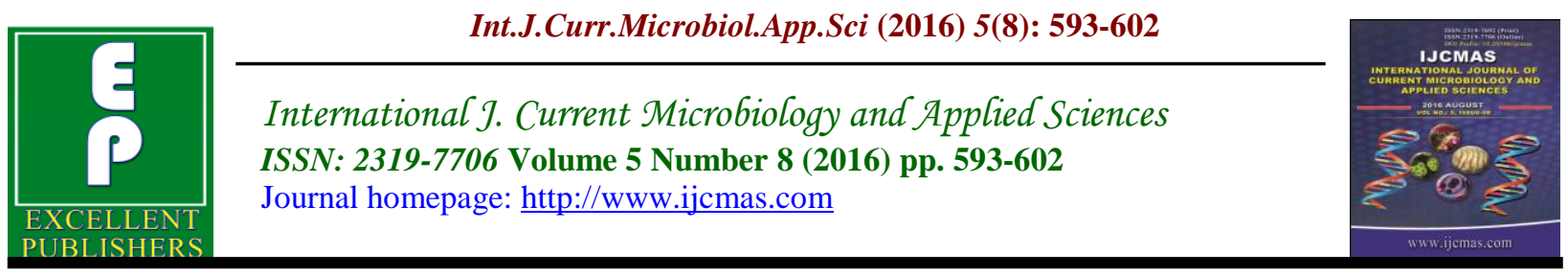

Original Research Article

http://dx.doi.org/10.20546/ijcmas.2016.508.066

\title{
The Role of Health Workers in Preventing Methamphetamine Addiction in Rural Thailand
}

\author{
Civilaiz Wanaratwichit $^{1^{*}}$ and Suthichai Sirinual ${ }^{2}$ \\ ${ }^{1}$ The Faculty of Public Health, Naresuan University, Bangkok Thailand \\ ${ }^{2}$ Sukhothai Provincial Public Health Office, Thailand \\ *Corresponding author
}

\begin{abstract}
A B S T R A C T
Keywords

Methamphetamine,

Health worker,

Prevention,

Health Promoting

Hospitals.

\section{Article Info}

Accepted:

23 July 2016

Available Online:

10 August 2016

The purposes of this study were to investigate the role of health workers in the Health Promoting Hospitals and the problems that they face in their role in the prevention of methamphetamine use in rural Thailand. A case study approach was used to investigate, analyze and synthesize the role of health workers. Eighteen participants from the health sector and seven participants from other sectors in Sawankhalok District, Thailand were included in the sample case studies. Data were collected through in-depth interviews and documentary analysis. Thematic analysis was applied when analyzing the data. The role of health workers in the prevention of methamphetamine addiction in rural Thailand including 1) Finding new cases of methamphetamine addiction, 2) counseling the identified cases and their parents 3) training the identified cases 4) monitoring the behavior of the trained cases in the community and 5) enhancing awareness of the problem of drug addiction in the children. The main problem facing the health workers was the fear of conflict with the cases' families while performing their monitoring activities. The findings involve mainly on community participation, proactive approach, and psychological aspect for the prevention of addiction. Therefore, it is essential that they be offered advanced training in the skills.
\end{abstract}

\section{Introduction}

Methamphetamine (MA) in tablet form is called Ya-ba. It is still the major drug of abuse in Thaiand, where, in 2014 it was the most used drug. The number of Ya-ba treatment also increased from 79,618 cases in 2008 to 144,942 cases in 2011 .

(Office of the Narcotics Control Board, 2011). Methamphetamine use affects to health problems including seizures and convulsions as well as weight loss, and severe psychological symptoms such as depression, hallucinations, and paranoia (Sommers, Baskin et al., 2006).Moreover, Drug abuse affect to society, the most obvious effects of drug abuse are stealing and robbery following by brawling and speeding motorcycle respectively(National statistical office, 2015). The Thai government currently has a policy which is focused on solving the problem of methamphetamine usage in Thailand (Office 
of Policy and Strategy, 2015; The Narcotics Control Board, 2015)

Although Thailand can successfully control the drug's production inside the country, illicit drugs produced in neighboring countries, Laos and particularly Myanmar, still enter Thailand to satisfy the high demand for the drug (The Narcotics Control Board, 2015). The border areas in the north of Thailand are the major area from where methamphetamines spread into Thailand(The Narcotics Control Board, 2015). These areas are therefore high risk areas for the use of methamphetamine as well as being the source. All provinces in the north of Thailand have been facing with methamphetamine problems. They strived to make the solution. For example, Sukhothai Province is one of strengthening provinces among northern Thailand on preventing and solving methamphetamine problems. After solution more than 50 percent of villages in Sukhothai Province had no problems(The Narcotics Control Board, 2015). Therefore, in this case was interesting to study.

Methamphetamine addiction is a complex problem, encompassing often severe health problems, social stigma, and illegality. The problem cannot be successfully solved by medical treatment alone, nor just by law enforcement. Recidivism of drug addicts is a significant problem which impacts all sectors of the community, including the individual, the individual's family and social group, the community generally, and also the public sector including law enforcement agencies and medical services(Mitrpracha, 2014). The factors affecting recidivism can be categorized into personal factors, such as lack of awareness of the effects of the drug, disbelief in their likelihood of becoming an addict, and there being no apparent symptoms of addiction readily identifiable. Other factors can be categorized as being social and environmental, such as having addicted friends, poor social networks, and family attitudes based on ignorance of the problem or lack of family cohesion and support (Mitrpracha, 2014). Both the personal factors and the social and environmental factors are very local matters. Therefore, solutions to the problem must be found at the local and community levels for prevention of addiction and subsequent counseling and support of ex-addicts. The public health sector is therefore an essential element in methamphetamine prevention, indicating the importance of the role of health workers in local rural areas.

Solving the methamphetamine problem is a focus of Thai government policy. The national management structure for narcotics control consists of the Narcotics Control Board (ONCB) which sets policy within the Prime Minister's Department. Implementation of the policy is the responsibility of the Narcotics Control Center at the national level, together with Provincial, District and Sub-district centers for implementation down to the local level. Strategies of prevention and suppression of methamphetamine of Thailand emphasize the strengthened of participation of all sectors in the society(The Narcotics Control Board, 2015). The committees of the district Narcotics Control Centers cover the District and Sub-District areas, and include members from various government ministries, such as Public Health, the Police Service, and local administration as well as from the community. Health workers (Public health workers and nurses) who are members of this committee in the rural areas are the main stakeholders who were considered in this research.

In Thailand, the role of health workers at the Sub-District level is to provide primary health care. This includes treatment, prevention, promotion, and rehabilitation. In the case of methamphetamine usage, the 
mission of health workers mainly focus on a proactive approach to the prevention of methamphetamine usage and addiction such as health education, life skills, counseling, and surveillance of drug users, by community participation (Suphawong, Chunharat et al., 2009) which was assigned on the manual of Health Promoting Hospitals of Ministry of Public Health. However, information on role of health workers for the prevention of methamphetamine addiction in the practical and the real situation is limited. The obvious knowledge on the roles of health workers who work in the community lead to effectively service in district and sub-district levels and more access for methamphetamine use according to the study of Burnhams, Dada, \& Myers, (2012) studying in the clients who reported substance use found that district social services were a way improving access to services for people from underserved poor and rural communities (Burnhams et al., 2012).

Therefore, it is very important that we study the effective role of health workers working in and with the community. The purposes of this study were therefore to investigate the roles of health workers in the prevention of methamphetamine addiction in rural Thailand and to investigate the problems faced by health workers in the prevention of methamphetamine addiction in rural Thailand in order to provide information to support the planning of development programs for health workers and to be a practice guideline for other areas of intervention in the prevention of methamphetamine usage and addiction.

\section{Materials and Methods}

\section{Study design and population}

A case study (Khairul B.M. Noor, 2008) was used to explore and describe the roles of health workers and problems faced by them in the role of prevention of methamphetamine usage and addiction, by exploring their local experiences and practices in rural areas.

There are nine districts in Sukhothai province in the north of Thailand in which 118 health centers are located. One district, Sawankhalok District, with 15 health centers were selected for the study. This district was selected as having the best practice model for the prevention and suppression of methamphetamine abuse and addiction in a rural area, with a high level of participation from all sectors of the communities. The selection was recommended by the Provincial Public Health Office in Sukhothai Province. This is termed the Sukhothai Model for our purposes. Qualitative data were gathered in in-depth interviews (Boyce and Neale, 2006) and documentary study of the 25 participants, which included 15 health workers in the various Health Promoting Hospitals (two nurses, five public health workers, eight heads of Health Promoting Hospitals).

Three other members of the district health management committee made up the numbers of participants from the Health Sector. Of the 7 other participants from other sectors, five were members of the committees of Narcotics Control Center at the district Centers (one police officer, one minor district chief, one head of local administration, two community leaders), and two volunteers. Every participant had a role related to the prevention of methamphetamine usage and addiction in the study area for at least the previous two years.

\section{Data collection}

The in-depth interviews began with semistructured questions and data were collected in 2015.This step was used to help clarify 
the roles of health workers on the prevention of methamphetamine usage, and the problems faced by health workers in that activity. All data were fully recorded by electronic recorder and the main points were noted. Additionally, a documentary study of the performance records of the project and the outcomes so far achieved. Project plans, committee meeting minutes, activity diaries regarding project activities, and reports of outcomes, were included in the documentary study.

\section{Statistical analyses}

The qualitative data were analyzed by thematic analysis(Braun, 2006). All records were read and reviewed several times. The information was coded to indicate the appropriate theme, checked and used to develop the themes of the roles of the health workers was undertaken within the framework of primary and secondary prevention measures(Starfield et al., 2008) and the district health system(Tarimo, 1991), in accordance with the health care system reforms.

\section{Results and Discussion}

\section{The roles of health workers in the prevention of methamphetamine addiction}

The roles of the health workers in this situation were categorized into five domains: Theme 1 was finding new cases of methamphetamine addiction, with three subcategories emerging: participation in the village community, screening for drug users, and Identifying addicts. Theme 2 was an emerging theme regarding the counseling of the identified cases and their parents. Two sub-categories emerged under this theme: the need to provide information to the addicts and their families, and encourage and support the addicts to make good decisions on participation in the training programs. Theme 3 was the training of the addicts in modifying their behaviors. This comprises two sub-themes: being the main organizer and, secondly, ongoing interaction with the trainer. Theme 4 was monitoring the behaviors of the trained cases in the community and, finally, Theme 5 was enhancing awareness in all the children in the communities, including a sub-theme of health education in schools and also the participation in the teaching project by the police in the schools (table 1)

\section{Finding New Cases}

This is the first role of health workers in the prevention process. In this step, the health workers had to work altogether with the District and Sub District Narcotics Control Committee.

Community participation is essential to find new cases of use and addiction. This role includes working with the committee and within the village community to identify new cases. Step 1 was convening meetings with project participants who included representatives of each household in the village to provide information anonymously about addicts and users.

The focus then turned to verifying and confirming the potential cases, according to the information provided. Step 2 was the screening for potential addicts by the health workers and other members of committee undertaking screening by urine testing.

This was termed primary confirmation. Step 3 was for the health workers to inform the results to other committee members to consider further action on and interviewing of identified cases. 


\section{Counseling the cases and their parents}

The health worker then undertook the role of counselor. Other participants, such as the police officers and health committee members were not involved in the counseling of the addicts and their families. This was done to create a good, nonthreatening personal relationship with the addicts, and their family. Counseling includes providing information on the advantages and disadvantages of training for behavior modification, informing the addicts on the appropriate decisions that they could make, and encouraging and enabling good decision making by the addict and their family. Such decisions as attending the training provided for behavior modification or the consequences of refusing to attend. The families strongly convinced their son or daughter to participate the training. Cases rejecting training would be forwarded to other members of the Committee for management, which included taking the matter to the police for legal action.

\section{As an example from a health worker}

"We do not want the case was put in to prison. We try to provide information on the problem solving approaches available so that they can make informed decisions, especially, the decision to modify their behavior by attending the training. Most of the parents of drug addicts try to motivate their children to attend. Health Worker 4

\section{Training the cases for modification of their behaviors}

The objective of this role was to provide behavior modification in the cases. The training includes 1) being the main organizer of training meetings and 2) being the trainer for behavior modification strategies, working with stakeholders to teach these strategies, to provide knowledge and information particularly on life skills for protection against further methamphetamine use, such as building a positive attitude in their life, improving spiritual, and towards others; promoting good thinking, good behavior and enhancing self-esteem. It was important that only properly trained health workers filled this role.

\section{As an example from a health worker}

"...We have to make them trust us. We stayed with them [the cases] during the day and night time. We kindly taught and provided activities following to the manual of training that we had been trained on activities to improve their self-esteem, activities to support good thinking and so on..." Health Worker 6

\section{Monitoring the behaviors of the trained cases}

The fourth role involves the on-going monitoring of the risky behaviors of the trained cases in the community associated with methamphetamine use, by such activities as visiting the addicts in their home and family environment. Such visits were made with subsequent reporting on the performance of each case to the provincial level.

\section{As an example in a health worker:}

"After training the cases, we visited the trained cases at their home in their communities for monitoring their behavior and assessing their needs as well as planning support. We would then report the data to a committee at the provincial level. We had to do this activity because it is a policy of the national level." Health Worker1

\section{Enhancing awareness in children}

The health worker acts as a teacher and a supporter. The health workers provide health 
education in the schools on the harms of drug use and capacity of the children to protect themselves against drugs. Such education sessions occurred only once to twice per year. The health workers were joined in activity by members of the police service.

\section{As an example in a member of the district health management committee}

"Health education in the schools is a regular mission for staff in health promoting hospital including the prevention of drug using. They also have to teach it" A member of the district health management committee 3

The problems faced by health workers in the prevention of methamphetamine addiction

A significant problem faced by the health workers was the fear of conflict with the case's family and with other people in the community while performing monitoring activities of the trained cases. Families wish to avoid the stigma attached to having a drug addict in the family, and do not want to be 'singled out' in this way, fearing it will create negative perceptions in their community. In small rural communities this is a significant social problem, and can result in social isolation and being shunned by other members of the community. This has resulted in less monitoring activity than is necessary or desirable, reducing the effectiveness of the program.

\section{As an example in a health worker}

"Actually, I do not want to visit the case's family at home. There is a risk of conflict with them. They do not want to face their eyes and hear the poor words from other families such as saying that "their son was trained already so he is not related to the drug and why you come to meet him again" they care about view of neighborhoods" Health Worker 5.

A further problem was simply working with the committee at night. Sometimes, the necessary action for confirming suspicious cases is taking a urine sample during the night, for subsequent testing. However, this is difficult for woman health workers. However, other board members have cooperated by taking the samples for the health workers.

\section{As an example in a member of the committee}

"It's not easy for a Thai woman that was going to work at night with men and in a dangerous job. Moreover, in the morning the health worker have to take care of patients in the Health center so we were willing to work for her" Member of the Committee 2.

The roles of health workers in preventing methamphetamine addiction in rural areas were in accordance with the Action Plan of the Narcotics Control Board, Thailand for drug prevention and solution which focuses on the protection of groups potentially at risk, such as school children, and on screening for treatment and on community participation (The Narcotics Control Board, 2015).

The main roles of health workers involved participation with the District and Sub District Narcotics Control Committee such as local police, local administration as well as community members. The methamphetamine addiction is a high sensitive problem and stigma. If this problem is solved by community participation, methamphetamine addiction will be decrease (Sherman et al., 2009). Moreover, the finding new cases role was mainly supported by society in the 
communities made this role successful. According to the previous study, it was found that social support is an high important role in the completion of substance abuse treatment for persons from poor communities in Cape Town, South Africa (Myers et al., 2010).

The roles clearly involve the psychological aspects, especially the counseling of suspicious cases and their parents. It is very important because relying completely on law enforcement agencies cannot entirely solve the problem of addiction. The success of the prevention activity and the solution to methamphetamine addiction is not only dependent on legal measures and police action, but also requires professional psychological support (Birckmayer et al., 2008).

Basically, prevention of health problem consists of primary, secondary, and tertiary levels(Birckmayer et al., 2008). The result of this study indicated that roles of health workers emphasized and highlighted on the primary and secondary prevention. Primary prevention was enhancing children's awareness of the problem to alleviate future activities leading to addiction as promoting health prior to the development of disease or health problem(Starfield et al., 2008). Secondary prevention is to detect the health problem in the early stages(Starfield et al., 2008). Results of study showed the best procedure for secondary prevention of methamphetamine addiction includes identifying addicts, providing training for addicts, and monitoring in community of risky behaviors leading to the use of drugs.

Training for addicts purposed to change their thinking, enhance self-esteem, modify their behaviors, and lead to stop abuse in line with the study of Houmhoul, Ruchiwit \& Somprasert, (2015) which found that a program enhancing self-esteem can promote self-esteem among adolescent patients with amphetamine dependence(Houmhoul et al., 2015)

Training is a highly important role for health workers, however, can only be effectively performed by health workers who have been trained in this program.

Mass media or school based health education alone has not achieved the desired changed behaviors among the adult or youth population(Birckmayer and Fisher, 2008).In the current study we found that the health workers role of enhancing awareness in children refuse to accept or use illegal drugs, or to change their risky behaviors leading to methamphetamine use, is currently only to be found in health education programs in school. This indicates an urgent need for more general and broader primary prevention activities in the wider community, and in the student population.

The monitoring role of health workers was addressed with a difficult problem. Visiting and interacting with the families of the trained cases brings social condemnation, shame and stigma on the families; at least, there is a strong perception by the family members. This causes the families to deny the health workers access to perform their role, therefore, the monitoring role in the trained cases has a low success. This in turn causes a feeling of fear in the health workers and creates conflict between the health workers and the community members. This highlights a problem with the policy of the Ministry of Public Health which focuses on the monitoring role for decreasing the recidivism of drug addicts, a role that the Health workers have difficulty in fulfilling, as discussed (The Narcotics Control Board, 2015). 
Table.1 Five themes of the roles of health workers in the prevention of methamphetamine addiction in rural Thailand

\begin{tabular}{|l|l|}
\hline \multicolumn{1}{|c|}{ Themes } & \multicolumn{1}{c|}{ Sub-themes } \\
\hline $\begin{array}{l}\text { 1. Finding the new cases of } \\
\text { methamphetamine addiction }\end{array}$ & $\begin{array}{l}\text { 1.1Participation in the village community } \\
\text { 1.2Screening for drug users } \\
\text { 1.3Identifying addicts }\end{array}$ \\
\hline 2. Counseling the cases and their parents & $\begin{array}{l}\text { 2.1 Provide information to the addicts and their } \\
\text { families } \\
\text { 2.2 Encourage and support to make good decision }\end{array}$ \\
\hline $\begin{array}{l}\text { 3. Training the cases for modification of } \\
\text { their behaviors }\end{array}$ & $\begin{array}{l}\text { 3.1 Being the main organizer } \\
\text { 3.2 Being trainer }\end{array}$ \\
\hline $\begin{array}{l}\text { 4. Monitoring the behaviors of the } \\
\text { trained cases in community }\end{array}$ & $\begin{array}{l}\text { 4.1 Monitoring the behaviors of the trained cases in } \\
\text { community }\end{array}$ \\
\hline 5.Enhancing awareness in children & $\begin{array}{l}\text { 5.1. Health education in school } \\
\text { 5.2 Participation in a teaching project by polices in } \\
\text { school }\end{array}$ \\
\hline
\end{tabular}

The monitoring, however, is still highly important for prevention of methamphetamine addiction. Prior research has clearly demonstrated that the role of monitoring in the trained cases in community is of primary importance in the prevention of relapse of the cases. The factors affecting recidivism of drug addicts are related to various issues of the individual addict as well as social and environment factors (Mitrpracha, 2014). Moreover, Rodseeda et al., (2010)found that risky personal behaviors and risky community situations are significantly associated with the relapse of methamphetamine users (Rodseeda et al., 2010). Therefore, the monitoring in trained cases in community is highly essential to be revised at the national policy level in the appropriate responsibility of health workers.

In conclusion, the role of health workers in preventing methamphetamine addiction in rural Thailand importantly includes participation with the District and Sub District Narcotics Control Committee and community members to meet the need that often faced with complex problems and sensitive issues. The roles as proactive approach are not only promoting health prior to addiction but also identifying addicts for solution their behaviors and to stop abuse. However, the prevention after addict was more focused.

The psychological aspect is the most important procedure, in particular, the counseling. The role of counseling demands a high level of skill and understanding on the part of the health worker. To enable them to effectively and safely perform in the role, acquiring the skills is necessary, making it essential that intensive training is available to them. Government policies governing the role of health workers in monitoring the trained cases in community should be evaluated and reviewed. The prevention for new cases of methamphetamine addiction must be acknowledged and recognised in the National Policies.

\section{Acknowledgements}

We thank all the participants in Sawankhalok District, Sukhothai province as well as Faculty of Public Health, Naresuan University, Thailand. 


\section{References}

Birckmayer, J., Deborah, A., Fisher, Harold, D., Holder, George, S., Yacoubian. 2008. Prevention of methamphetamine abuse: can existing evidence inform community prevention? J. Drug Edu, 38(2):147-65.

Boyce, C., Neale, P. 2006. Conducting indepth interviews: a guide for designing and conducting in-depth interviews for evaluation input: Pathfinder International.Tool Series, Monitoring and Evaluation-2. http://www. pathfind. org/ site/DocServer/ m_e_tool_series_indepth_interviews.p df? docID $=6301$.

Braun, V., Clarke, V. 2006. Using thematic analysis in psychology. Qual. Res. Psychol., 3: 77-101.

Burnhams, N.H., Dada, S., Myers, B. 2012. Social service offices as a point of entry into substance abuse treatment for poor South Africans. Subst Abuse Treat Prev Policy, 7(22):7-22.

Houmhoul, T., Ruchiwit, M., Somprasert, C. 2015. Self-esteem enhancement for adolescent patients with amphetamine dependence. J. Psychiatric Nursing And Mental Health, 28(1): 81-91.

Khairul, B.M., Noor. 2008. Case study: A strategic research methodology. American J. Appl. Sci., 5(11): 1602-4.

Mitrpracha, T. 2014. factors influencing recidivism of juvenile delinquents after their release. Pathumthani University academic J., 6(1): 34-46.

Myers, B.J., Pasche, S,. Adam, M. 2010. Correlates of substance abuse treatment completion among disadvantaged communities in Cape Town, South Africa. Substance Abuse Treatment, Prevention, and Policy, 5(3):1-7.

National statistical office.2015.A survey of public opinion about the prevalent drug situation according to the strategy of prevent and resolve drug problems. Bangkok: National statistical office, Ministry of Information and Communication Technology.

Office of Policy and Strategy.2015.Strategies, goals, and indicators of Ministry of Public Health for the year 2015. In: Health MoP, editor. Bangkok: Office of Policy and Strategy, Ministry of Public Health., 1-39.

Office of the Narcotics Control Board. 2011.Thailand Narcotics Control Annual Report 2011. Bangkok: Office of the Narcotics Control Board, Ministry of Justice, Thailand. Report No.: No. 1-19-2555 Contract No.: ISSN 978-616-7187-97-6.

Rodseeda, P., Ratanasiri, A., Kanato, M., Pinitsoontorn, S., Chiawiriyabunya, I. 2010. An exploratory study on association between family relationship and relapse among methamphetamine users in Compulsory Treatment System of Khon Kaen and Yasothon Provinces. J. Medical Association of Thailand, 93 (Suppl 3):S1-5.

Sherman, S.G., Sutcliffe, C., Srirojn, B., Latkin, C.A., Aramratanna, A., Celentano, D.D. 2009.Evaluation of a peer network intervention trial among young methamphetamine users in Chiang Mai, Thailand. Social Sci. Med., 68(1):69-79.

Sommers, I., Baskin, D., Baskin-Sommers, A. 2006. Methamphetamine use among young adults: Health and social consequences. Addictive Behaviors, 31(8):1469-76.

Starfield, B., Hyde, J., Ge'rvas, J., Heath, I. 2008. The concept of prevention: a good idea gone astray? J. Epidemiol. Community Health, 62(7):580-3.

Suphawong, C., Chunharat, S., Sirilak, S., 
Damrikarnlert, L., Sriwanichakora, S., Vedhsuthanon, K. 2009.Manual of sub-district health promoting hospital 2, editor. Bangkok: The War Veterans Organization Publishing.

Tarimo, E.1991. Towards a healthy district : organizing and managing district health systems based on primary healthcare. WHO. Guides- Non
Classroom Use(055). Available from http://files.eric.ed.gov/fulltext/ED3375 48.pdf.

The Narcotics Control Board.2015. Action plan for drug prevention and solution. Bangkok: Office of the Narcotics Control Board, Ministry of justice.

\section{How to cite this article:}

Civilaiz Wanaratwichit and Suthichai Sirinual 2016. The Role of Health Workers in Preventing Methamphetamine Addiction in Rural Thailand. Int.J.Curr.Microbiol.App.Sci. 5(8): 593-602. doi: http://dx.doi.org/10.20546/ijcmas.2016.508.066 